\title{
EFEKTIVITAS STIMULASI KUTANEUS : SLOW STROKE BACK MASSAGE TERHADAP PENURUNAN INTENSITAS NYERI OSTEOARTHRITIS PADA LANSIA DI PUSKESMAS SEI SEMAYANG DAN MULYOREJO KECAMATAN SUNGGAL KABUPATEN DELI SERDANG
}

\author{
Johani Dewita Nasution, Sri Siswati \\ Poltekkes Kemenkes Medan Jurusan Keperawatan
}

\begin{abstract}
Abstrak
Kondisi alam dan masyarakat saat ini sangat kompleks sehingga banyak masalah kesehatan yang muncul cukup dominan sepeti osteoarthritis pada lansia. Stimulasi Kutaneus : Slow Stroke Back Massage merupakan salah satu terapi non farmakologis yang ditawarkan untuk menurunkan intensitas nyeri dengan teknik usapan perlahan pada punggung yang dapat mengakibatkan vasodilatasi pembuluh darah. Penelitian ini bertujuan untuk mengidentifikasi efektivitas Stimulasi Kutaneus : Slow Stroke Back Massage terhadap penurunan intensitas nyeri Osteoarthritis pada Lansia di Puskesmas Mulyo Rejo dan Sei Semayang Kec. Sunggal Kab. Deli Serdang. Desain penelitian yang digunakan dalam penelitian ini adalah quasy-eksperiment. Stimulasi Kutaneus : Slow Stroke Back Massage dalam penelitian ini dilakukan secara teratur dalam waktu 30 menit selama 14 hari berturut-turut mulai dari tanggal 13 Juli - 23 Agustus. Berdasarkan uji hipotesis estimasi proporsi diperoleh sample sebanyak 68 orang, sampel ini terbagi dalam 2 kelompok 34 orang kelompok intervensi dan 34 orang kelompok kontrol. Selama penelitian berlangsung terdapat responden yang gugur sebanyak 7 orang sehingga sampel pada kelompok intervensi menjadi 30 orang dan kontrol 30 orang. Pada kedua kelompok dilakukan pengukuran intensitas nyeri pre dan post intervensi. Dan datanya dicatat dalam lembar observasi intensitas nyeri. Kemudian data penelitian ini di analisa dengan uji statistik deskriptif dan inferensial. Berdasarkan hasil analisa data dengan uji paired t-test menunjukkan bahwa intensitas nyeri kelompok intervensi berbeda antara pre-post Stimulasi Kutaneus : Slow Stroke Back Massage $(\mathrm{t}=2.03$, $\mathrm{p}=0.00$. Selanjutnya dengan uji independent $t$-test, penelitian ini juga menemukan bahwa intensitas nyeri kelompok intervensi berbeda dengan kelompok kontrol $(\mathrm{p}=0.00)$. Penemuan ini menunjukkan bahwa terdapat penurunan intensitas nyeri yang signifikan setelah Stimulasi Kutaneus : Slow Stroke Back Massage secara teratur. Juga terdapat perbedaan intensitas nyeri yang signifikan bila dibandingkan dengan kelompok kontrol. Kesimpulan dari penemuan penelitian ini menunjukkan bahwa Stimulasi Kutaneus : Slow Stroke Back Massage efektif terhadap penurunan intensitas nyeri osteoarthritis pada lansia.
\end{abstract}

Kata kunci : lansia, osteoarthritis, nyeri, stimulasi kutaneus : slow stroke back massage

\section{PENDAHULUAN}

Masalah-masalah kesehatan akibat penuaan terjadi pada berbagai sistem tubuh. Berdasarkan informasi data yang dikutip dari buku ajar geriatri, penyakit yang paling tinggi presentasenya adalah osteoartritis, yaitu mencapai 49\% (Kuntaraf, 2002). Osteoartritis adalah penyakit pada sendi-sendi penahan berat tubuh yang bersifat progresif, non inflamasi, nonsistemik, dan recurrent (Reeves, 2009).

Prevalensi osteoartritis lebih banyak terjadi pada usia di atas 35 tahun, terutama wanita di atas 55 tahun (Reeves, 2009). Dalam suatu survey radiografi pada wanita di bawah usia 40 tahun hanya $2 \%$ yang mengalami osteoartritis, pada usia 45-60 tahun mencapai 30\% sementara pada usia di atas 61 tahun lebih dari $65 \%$ (Noer, 2006). Dari hasil observasi dari berbagai Rumah Sakit ditemukan bahwa osteoartritis lebih banyak menyerang wanita. Berdasarkan hasil studi pendahuluan di Puskesmas
Sei Semayang dan Mulyorejo Kecamatan Deli Serdang didapatkan bahwa jumlah lanjut usia yang selalu kontrol adalah 136 orang dan sebanyak 112 orang berjenis kelamin perempuan serta 87 orang diantaranya menderita osteoartritis.

Stimulasi kutaneus, distraksi, relaksasi, imajinasi terbimbing dan hipnosis adalah contoh intervensi non farmakologis yang sering digunakan dalam keperawatan untuk mengelola nyeri. Pada osteoartritis, umumnya pengelolaan nyeri dilakukan dengan stimulasi kutaneus: terapi panas/dingin, latihan/aktifitas fisik dan distraksi (Reeves, 2009; Koopman, 2007). Sementara itu, beberapa modalitas fisik lain seperti masase, terapi yoga, akupresure, akupuntur, dan terapi spa masih belum terbukti nilainya.

Salah satu tehnik memberikan masase adalah tindakan masase punggung dengan usapan yang perlahan (Slow-Stroke Back Massage). Usapan dengan lotion/oil memberikan sensasi hangat dengan mengakibatkan dilatasi pada pembuluh darah lokal (Kenworthy et al, 2002). 
Vasodilatasi pembuluh darah akan meningkatkan peredaran darah pada area yang diusap sehingga aktivitas sel meningkat dan akan mengurangi rasa sakit serta menunjang proses penyembuhan luka (Kusyati E, 2006; Stevens, 2009). Sensasi hangat juga dapat meningkatkan rasa nyaman (Reeves, 2009). Nilai terapeutik yang lain dari masase punggung termasuk mengurangi ketegangan otot dan meningkatkan relaksasi fisik dan psikologis (Kusyati E, 2006). Beberapa penelitian juga telah mengidentifikasi manfaat dari slow-stroke massage ini. Salah satunya adalah penurunan secara bermakna pada intensitas nyeri dan kecemasan serta perubahan positif pada denyut jantung dan tekanan darah, yang mengindikasikan relaksasi pada pasien lansia dengan stroke (Mok, E et al, 2004).

Salah satu penelitian terkait Stimulasi Kutaneus : Slow Stroke back massage adalah penelitian yang dilakukan oleh Zuliani, dkk (2013) tentang pengaruh Stimulasi Kutaneus : Slow Stroke back massage terhadap penurunan nyeri haid (dismenorea) yang hasilnya menunjukkan adanya pengaruh Stimulasi Kutaneus : Slow Stroke back massage terhadap penurunan nyeri haid (dismenorea) dengan nilai signifikan $\mathrm{p}=0,00$. Selain itu penelitian Ni Putu Haryska, WD, dkk (2015) tentang Intervensi Slow Stroke back massage lebih menurunkan tekanan darah daripada Latihan deep Breathing pada wanita middle age dengan Pre-hypertension yang hasilnya juga signifikan dengan nilai $\mathrm{p}=0,00$.

\section{METODOLOGI PENELITIAN}

Desain penelitian yang digunakan dalam penelitian adalah rancangan Quasy-Eksperiment yaitu rancangan yang berupaya mengungkapkan hubungan sebab akibat dengan cara melibatkan kelompok kontrol disamping kelompok eksperimental (Nursalam, 2003). Penentuan besar sampel dilakukan dengan menggunakan uji hipotesis estimasi proporsi. Sehingga diperoleh besar sampel adalah 68 orang yang terbagi menjadi 34 orang pada kelompok intervensi dan 34 orang kelompok kontrol. Selama penelitian berlangsung terdapat responden yang gugur sebanyak 7 orang sehingga sampel pada kelompok intervensi menjadi 30 orang dan kontrol 30 orang. Pada kedua kelompok dilakukan pengukuran intensitas nyeri pre dan post intervensi. Dan datanya dicatat dalam lembar observasi intensitas nyeri. Kemudian data penelitian ini di analisa dengan uji statistik deskriptif dan inferensial.

\section{Hasil Penelitian \\ 1. Karakteristik responden}

Karakteristik Responden terdiri dari usia, jenis kelamin, suku, riwayat pendidikan, pekerjaan dan lokasi nyeri.

Tabel 1. Karakteristik Demografi Responden

\begin{tabular}{|c|c|c|c|c|}
\hline \multirow{2}{*}{ Karakteristik Data Demografi } & \multicolumn{2}{|c|}{ Kel. Intervensi } & \multicolumn{2}{|c|}{ Kel. Kontrol } \\
\hline & Frekuensi (n) & Persentase (\%) & Frekuensi (n) & Persentase (\%) \\
\hline \multicolumn{5}{|l|}{ 1. Usia (tahun) } \\
\hline $60-74$ & 5 & 17 & 6 & 20 \\
\hline $75-90$ & 25 & 83 & 24 & 80 \\
\hline & \multicolumn{2}{|c|}{ Mean $=76$} & \multicolumn{2}{|c|}{ Mean $=74$} \\
\hline \multicolumn{5}{|l|}{ 2. Jenis kelamin } \\
\hline Perempuan & 30 & 100 & 30 & 100 \\
\hline Laki-laki & 0 & 0 & 0 & 0 \\
\hline \multicolumn{5}{|l|}{ 3. Suku } \\
\hline Jawa & 17 & 50 & 17 & 50 \\
\hline Minang & 9 & 30 & 6 & 20 \\
\hline Batak & 6 & 20 & 9 & 30 \\
\hline \multicolumn{5}{|l|}{$\begin{array}{l}\text { 4. Riwayat } \\
\text { pendidikan }\end{array}$} \\
\hline $\mathrm{SD}$ & 18 & 60 & 20 & 67 \\
\hline SMP & 10 & 33 & 8 & 26 \\
\hline SMU & 2 & 7 & 2 & 7 \\
\hline \multicolumn{5}{|l|}{ 5. Pekerjaan } \\
\hline Ibu rumah tangga & 21 & 70 & 20 & 65 \\
\hline Wiraswasta & 4 & 13 & 3 & 10 \\
\hline dan lain-lain & 5 & 17 & 7 & 25 \\
\hline \multicolumn{5}{|l|}{ 6. Lokasi Nyeri } \\
\hline Pinggul & 24 & 80 & 23 & 75 \\
\hline Lutut & 6 & 20 & 7 & 25 \\
\hline
\end{tabular}


Berdasarkan tabel 1 diketahui bahwa usia responden sebagian besar berada pada rentang usia 7690 tahun $83 \%$ ( 25 orang) pada kelompok intervensi dan $80 \%$ (24 orang) pada kelompok kontrol, jenis kelamin $100 \%$ perempuan, suku pada kelompok intervensi dan kontrol sebagian besar adalah suku Jawa 50\%, riwayat pendidikan sebagian besar SD sebanyak $60 \%$ pada kelompok intervensi dan $67 \%$ pada kelompok kontrol, pekerjaan sebagian besar ibu rumah tangga sebanyak $70 \%$ pada kelompok intervensi dan $65 \%$ pada kelompok kontrol, untuk lokasi nyeri lebih dari setengah responden mengeluh nyeri dibagian pinggul $80 \%$ pada kelompok intervensi dan $75 \%$ pada kelompok kontrol.

\section{Intensitas Nyeri}

Tabel 2. Perbedaan intensitas nyeri pre dan post pada kelompok intervensi

\begin{tabular}{lcccc}
\hline Kelompok & $\begin{array}{c}\text { Intensitas } \\
\text { Nyeri }\end{array}$ & $\begin{array}{c}\text { Mean } \\
\text { difference }\end{array}$ & T & P \\
\hline Intervensi & pre - post & 3.871 & 2.03 & 0.00 \\
\hline
\end{tabular}

Berdasarkan tabel 2 diketahui bahwa perbedaan intensitas nyeri pre dan post stimulasi kutaneus : slow stroke back massage pada kelompok intervensi adalah $\mathrm{p}=$ $0.00(\mathrm{p}<0.05)$.

Tabel 3. Perbedaan intensitas nyeri pre dan post pada kelompok kontrol

\begin{tabular}{ccccc}
\hline Kelompok & $\begin{array}{c}\text { Intensitas } \\
\text { Nyeri }\end{array}$ & $\begin{array}{c}\text { Mean } \\
\text { difference }\end{array}$ & T & P \\
\hline Kontrol & pre - post & 0.035 & 1.353 & 0.10 \\
\hline
\end{tabular}

Sedangkan berdasarkan tabel 3 diketahui bahwa perbedaan intensitas nyeri pre dan post pada kelompok kontrol adalah $\mathrm{p}=0.10(\mathrm{p}>0.05)$.

Tabel 4. Perbedaan Penurunan Intensitas Nyeri Antara Kelompok Intervensi dengan Kelompok Kontrol

\begin{tabular}{cccccc}
\hline Variabel & \multicolumn{3}{c}{$\begin{array}{l}\text { Kelompok } \\
\text { Intervensi }\end{array}$} & Kelompok Kontrol & $\begin{array}{c}\mathbf{p} \\
\text { value }\end{array}$ \\
\cline { 2 - 4 } $\begin{array}{c}\text { Mean } \\
\begin{array}{c}\text { Intensitas Nyeri } \\
\text { Post }\end{array}\end{array}$ & SD & Mean & SD & \\
& 2.63 & 1.14 & 6.81 & 3.38 & 0.000 \\
\hline
\end{tabular}

Berdasarkan tabel 4 diketahui bahwa perbedaan penurunan intensitas nyeri antara kelompok intervensi dan kelompok kontrol adalah $\mathrm{p}=0.00(\mathrm{p}<0.05)$ artinya terdapat perbedaan yang signifikan antara intensitas nyeri antara kelompok intervensi dengan kelompok kontrol.

\section{Pembahasan}

Sebelum dilakukan pemberian stimulasi kutaneus: slow-stroke back massage, semua subyek penelitian (100\%) mengalami nyeri sedang, yang diakibatkan oleh bagian-bagian tonjolan-tonjolan tulang atau kartilago yang remuk yang kemudian masuk ke dalam cairan sinovial dan akhirnya merangsang nosiseptor yang terdapat pada sendi dan periosteum (Reeves, 2009; Guyton \& Hall, 2007). Osteoartritis adalah nyeri yang bersifat recurrent, dengan demikian pengalaman nyeri sebelumnya membantu individu untuk dapat melakukan tindakan pada saat nyeri berikutnya sehingga nyeri yang dirasakan cenderung berada pada tingkat sedang. Setelah dilakukan stimulasi kutaneus: slow-stroke back massage, maka serabut saraf A beta yang banyak terdapat di kulit akan terangsang sehingga pintu gerbang tertutup dan stimulus nyeri tidak diteruskan ke otak. Di samping itu, endorphin juga dilepaskan sehingga kadarnya meningkat. Kedua hal tersebut menyebabkan terjadinya penurunan intensitas dan nilai skala nyeri yang dirasakan oleh responden penelitian. Hal ini dapat dilihat pada tabel 4, dimana $80 \%$ responden penelitian mengalami penurunan intensitas nyeri.

Berdasarkan hasil uji statistik independent t-test didapatkan nilai $p=0,00$. Dengan demikian $p<0,05$, maka Ho ditolak. Dari hasil analisa di atas dapat disimpulkan bahwa pemberian stimulasi kutaneus: slow-stroke back massage memiliki pengaruh terhadap intensitas nyeri osteoartritis pada lansia. Pemberian stimulasi kutaneus: slow-stroke back massage terbukti dapat menurunkan intensitas nyeri lansia dengan nyeri osteoartritis. Dengan demikian pemberian stimulasi kutaneus: slow-stroke back massage dapat dijadikan sebagai alternatif pilihan untuk menurunkan intensitas nyeri osteoartritis pada lansia secara non farmakologis yang relatif tidak menimbulkan efek samping.

\section{A. KESIMPULAN DAN SARAN}

\section{Kesimpulan}

Setelah dilakukan uji statistik Independent t- Test diperoleh hasil $\mathrm{p}=0.00$, nilai $\mathrm{p}<0,05$ maka Ho ditolak sehingga dapat disimpulkan bahwa pemberian stimulasi kutaneus: slow-stroke back massage mempengaruhi intensitas nyeri orteoartritis pada lansia.

\section{Saran}

1. Dapat memberikan stimulasi kutaneus dengan tehnik slow-stroke back massage sebagai salah satu alternatif intervensi keperawatan secara non farmakologis untuk membantu klien dengan nyeri osteoartritis.

2. Merupakan tindakan yang mudah, aman, tidak memerlukan banyak alat dan biaya sehingga perawat dapat mensosialisasikan cara melakukan stimulasi kutaneus ini kepada keluarga dan masyarakat luas khususnya lansia.

\section{DAFTAR PUSTAKA}

Arikunto, S. 2002. Prosedur Penelitian, Rineka Cipta, Jakarta

Billings, Diane Mc. Govern; Lillian Gatlin Stokes. 1982. Medical Surgical Nursing, The C.V Mosby Company, Toronto 
Daniel. 2006. OAINS Konvensional Masih Jadi Pilihan, http://www.majalahfarmacia.com/default.asp, Diakses tanggal 25 November 2018

Darmojo, B. 2005. Buku Ajar Geriatri (Ilmu Kesehatan Usia Lanjut), Balai Pustaka FKUI, Jakarta

Darmojo, B. 2010. Buku Ajar Geriatri (Ilmu Kesehatan Usia Lanjut) Edisi Ke-3, Balai Pustaka FKUI, Jakarta

Ellen, Martha Keene. 2000. Nursing Intervention \& Clinical Skill, 2rd edition, Mosby, USA

Guyton, Arthur C; Hall JE. 2007. Buku Ajar Fisiologi Kedokteran, editor Bahasa Indonesia : Irawati Setiawan Edisi 9, EGC, Jakarta

Hartono, M. 2000. Mencegah dan Mengatasi Osteoporosis, Puspa Swara, Surakarta

Hidayat, A.Aziz Alimul. 2007. Riset Keperawatan dan Teknik Penulisan Ilmiah, Salemba Medika, Jakarta

Hutapea, R. 2005. Sehat dan Ceria di Usia Senja, Rineka Cipta, Jakarta

Ignativicius, D.D. 2001. Medical Surgical Nursing, Saunders Company, USA

Kaufman, CE; Patrick A. McKee. 2006. Essentials of Pathofisiology, Little Brown \& Company, USA

Kenworthy, Snowley, Gilling. 2002. Common Foundation Studies in Nursing, Third Edition, Churchill Livingstone, USA

Koopman, WJ. 2007. Arthritis and Allied Conditions: A Textbook of Rheumatology, William \& Wilkins A Waverly Company, USA

Kozier, Barbara; Glenora Erb; Audrey Berman; Shirlee J. Snyder. 2004. Fundamental Nursing: Concept and Procedures. 8th edition. Pearson Prentice Hall, USA

Kulkarni, B; Bentley DE; R. Elliot. 2007. Arthritic Pain Is Processed in Brain Areas Concern With Emotions and Fear. http://www.interscience.com/journal/artritis, Diakses 6 November 2018

Kuntaraf, J. 2002. Olahraga Sumber Kesehatan, Advent Indonesia, Bandung

Kusyati, E. 2006. Keterampilan dan Prosedur Laboratorium Keperawatan Dasar, EGC, Jakarta
Long, B.C. 2006. Perawatan Medikal Bedah I, Yayasan Ikatan Alumni Pendidikan Keperawatan Padjajaran, Bandung

Lueckkeenotte, S.G. 2006. Gerontology Nursing, Mosby, Philadephia

Mok, E; Chin Pang Woo. 2004. The Effects of Slow-Stroke Back Massage on Anxiety and Shoulder Pain In Elderly Stroke Patients, http://www.sciencedirect.com/science, Diakses 30 October 2018

Noer, M. Sjaifoellah. 2006. Ilmu Penyakit Dalam, Balai Penerbit FKUI, Jakarta

Notoatmojo, Soekidjo. 2003. Metodologi Penelitian Kesehatan, Rineka Cipta, Jakarta

Nugroho, W. 2000. Keperawatan Lanjut Usia, EGC, Jakarta

Nursalam. 2003. Konsep dan Penerapan Metodologi Penelitian Ilmu Keperawatan : Pedoman Skripsi, Tesis dan Instrumen Penelitian Keperawatan, Salemba Medika, Jakarta

Potter, Patricia A; Anne Griffin Perry. 2007. Buku Ajar Fundamental Keperawatan: Konsep, Proses, dan Praktik Edisi 4 Volume 2, Renata Komalasari (penterjemah), 2005, EGC, Jakarta

Price, Silvia A. 2005. Patofisiologi : Konsep Klinik dan Proses-Proses Penyakit, EGC, Jakarta

Priharjo, R. 2003. Perawatan Nyeri : Pemenuhan Aktivitas Istirahat Pasien, EGC, Jakarta

Reeves, Charlene J; Gayle Roux, Robin Lockhart. 2009. Medical Surgical Nursing, Mc. Graw-Hill. Companies Inc, USA

Smeltzer SC, Bare B.G. 2006. Buku Ajar Keperawatan Medikal Bedah Edisi 8 Vol. 1. Agung Waluyo (penterjemah), 2001, EGC, Jakarta

Smeltzer SC, Bare B.G. 2006. Buku Ajar Keperawatan Medikal Bedah Edisi 8 Vol. 3. Agung Waluyo (penterjemah), 2001, EGC, Jakarta

Stevens, P.J.M. 2009. Ilmu Keperawatan Jilid 1 Edisi 2. Ed. Monica Ester., EGC, Jakarta.

Sugiyono. 1998. Statistik Untuk Penelitian, Alva Beta, Bandung 